\title{
IDENTIFICATION OF THE SHOCKWAVE EFFECT ONTO EXPLOSIVE ORDNANCE DISPOSAL (EOD) PERSONNEL DURING CONTROLLED AIRBLAST OF TNT CHARGE
}

\author{
G. Bienioszek* , S. Kciuk ${ }^{* * *}$, E. Krzystala***
}

\begin{abstract}
The aim of this study was to identify the effect of the shockwave emitted during explosion of the TNT charge onto Explosive Ordnance Disposal (EOD) Personnel. Within the work, the basic information about the air blast and its influence on the human body were discussed. The necessity of well fitted protective equipment application was highlighted. Detonations of the few different charge masses were performed. Pressure in the dummy ears and accelerations of its head were examined. The obtained records were compared with maximum allowable levels of those parameters taken from literature. It was noticed that even for small charges, which do not poses a threat for structures, the risk of body injury caused by the blast pressure cannot be neglected.
\end{abstract}

Keywords: blast shockwave, TNT air blast, pressure and acceleration measurements, Explosive Ordnance Disposal (EOD).

\section{Introduction}

Numerous data concerning the influence of the explosion wave onto structures are available in the literature (Ullah et al., 2017). However, there is a lack of information regarding the impact of direct explosion on the human body, as it is usually considered to be lethal injury. There are several professions inseparably connected to a high risk of close proximity explosions such as police and military pyrotechnics. Their equipment provides a good protection against the direct fire and fragmentations, but can be insufficient in order to mitigate pressure and inertial effects. Consequently, it may lead to bone cracks and fractures, as well as injuries to internal organs and brain trauma (Prat et al., 2017).

Essential factors that affect a human body during the explosion are therefore pressure and acceleration. Blast wave can be described i.a. by: maximum value of overpressure, positive phase duration and time of blast wave arrival (Ullah et al., 2017). Acceleration signals are used mainly to determine the injury risk factors such as e.g. Head Injury Criterion (HIC). However, they can be also used to calculate average acceleration values (Bienioszek et al., 2017), which in turn can be compared with the human tolerance levels (Eiband et al., 1959).

The proper processing of the recorded signals is also an important issue (Krzystała et al., 2016). NATO AEP-55 Vol. 2 (2011) recommends the use of appropriate low-pass filters in order to supersede the high frequency vibrations, which are damped by a soft tissue of a human body. However, available guidelines apply mainly for processing of the signals recorded during car crash accidents. Hence, the question arises whether they are fully adequate to analyse the explosion influence onto human body. Therefore, in article both the raw and filtered signals were presented.

MSc. Eng. Grzegorz Bienioszek: Institute of Theoretical and Applied Mechanics, Silesian University of Technology, Konarskiego 18a; 44-100, Gliwice; PL, grzegorz.bienioszek@polsl.pl

** PhD. Eng. Sławomir Kciuk: Institute of Theoretical and Applied Mechanics, Silesian University of Technology, Konarskiego 18a; 44-100, Gliwice; PL, slawomir.kciuk@polsl.pl

*** PhD. Eng. Edyta Krzystała: Institute of Theoretical and Applied Mechanics, Silesian University of Technology, Konarskiego 18a; 44-100, Gliwice; PL, edyta.krzystala@polsl.pl 


\section{Methods}

Acceleration measurements were conducted with the use of autonomous measurement system for the acquisition of rapidly changing signals (Szmidt et al., 2011). Pressure signals were recorded with the use of Kulite ${ }^{\circledR}$ HKS-375M sensor. Accelerometer was located in the dummy head, while pressure transducer was placed in the ear. The both of them were operating with $100 \mathrm{kHz}$ sampling rate. The initial configuration of the system was shown on the Fig. 1a. Distance between the dummy and the TNT charge centre was set to $3.5 \mathrm{~m}$ (Fig. 1b). The intention was to reflect situation in which the pyrotechnic is carrying the explosive on special pole. The charge was hanged on piece of rope connected to a wooden stick, so the explosion took place in the air, approximately at a chest level. Detonations of four different TNT charge masses were performed $(0.075,0.2,0.4$ and $1.0 \mathrm{~kg})$.
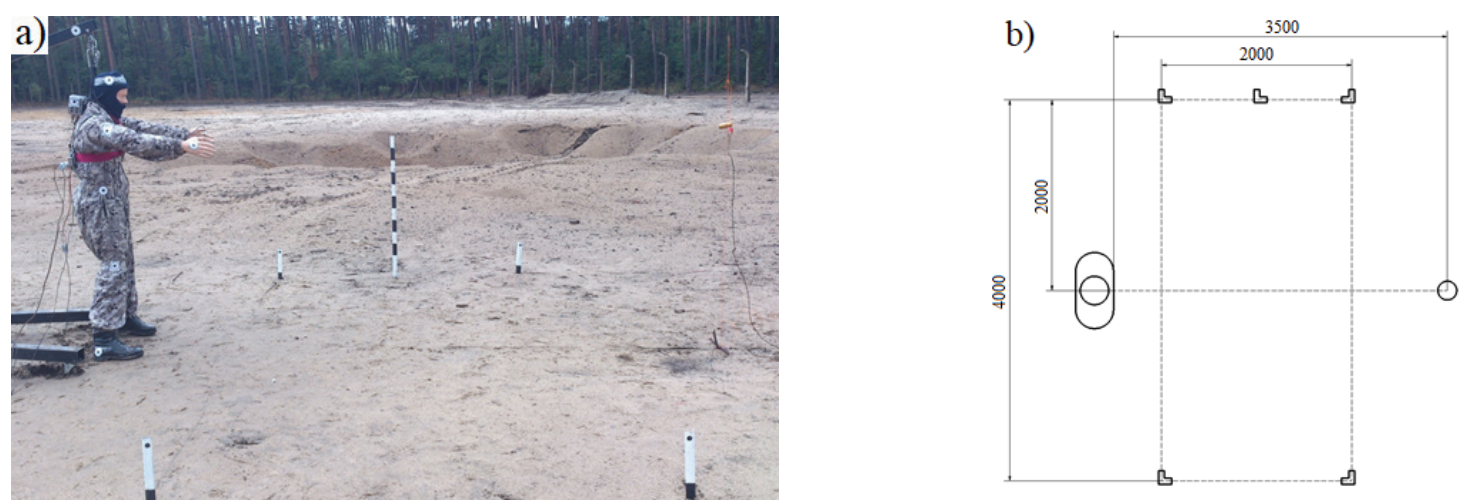

Fig. 1: The initial system configuration: a) overview, b) dimensional details

The recorded pressure pulse characteristic was compared with the theoretical pressure profile with the use of following equations (Ullah et al., 2017):

$$
\begin{gathered}
Z=\frac{R}{W^{1 / 3}} \\
P(t)=P_{0}+P_{s}\left(1-\frac{t}{t_{d}}\right), \quad 0<t \leq t_{d} \\
P_{S}=\frac{0.085}{Z}+\frac{0.3}{Z^{2}}+\frac{0.82}{Z^{3}} \\
t_{d}=1.2 \sqrt[6]{W} \sqrt{R} \\
t_{a}=0.34 \frac{R^{1.4} W^{-0.2}}{a_{0}}
\end{gathered}
$$

where:

$Z$ - scaled distance (proximity factor) $\left[\frac{\mathrm{m}}{\mathrm{kg}^{1 / 3}}\right]$,

$R$ - distance between the dummy and the centre of spherical TNT charge [m],

$W$ - mass of the TNT charge $[\mathrm{kg}]$,

$P(t)$ - positive blast pressure profile,

$P_{0}$ - ambient atmospheric pressure [MPa],

$P_{s}$ - blast overpressure $[\mathrm{MPa}]$,

$t_{d}$ - positive phase duration [ms],

$t_{a}$ - arrival time of blast wave [ms],

$a_{0}$ - sound speed in the undisturbed atmosphere equal to $0.34 \frac{\mathrm{m}}{\mathrm{ms}}$.

Investigation of the negative blast pressure phase was omitted intentionally since its magnitude and the scaled distance $Z$ were relatively small in current studies. According to the literature (Ullah et al., 2017) it can be neglected if $Z$ is lower than $20 \frac{\mathrm{m}}{\mathrm{kg}^{1 / 3}}$.

Maximum average acceleration in $10 \mathrm{~ms}$ time period was calculated by integration of recorded signal:

$$
|a|_{\text {avg_10ms }}=\max \left(\frac{\int_{t_{1}}^{t_{2}}|a| d t}{\Delta t}\right)
$$

where:

$a$ - recorded acceleration signal $[\mathrm{g}]$, 
$\Delta t=t_{2}-t_{1}-$ time period in which average acceleration was calculated (10 ms).

The Head Injury Criterion coefficient $\left(\mathrm{HIC}_{15}\right)$ was calculated for time duration of $15 \mathrm{~ms}$ with the use of following equation (NATO AEP-55 Vol. 2, 2011):

$$
H I C_{15}=\max \left\{\left(t_{2}-t_{1}\right)\left[\frac{1}{t_{2}-t_{1}} \int_{t_{1}}^{t_{2}} a(t) d t\right]^{2,5}\right\}
$$

where:

$t_{1}, t_{2}$ - initial and final times of the interval during which HIC attains a maximum value [s],

$a$ - recorded acceleration signal $[\mathrm{g}]$,

\section{Results}

The characteristic parameters of the pressure pulse recorded for the $1.0 \mathrm{~kg}$ of TNT, as well as their comparison with the expected theoretical values determined on the basis of the equations 3-5, were presented in Table 1. The scaled distance calculated from the formula (eq. 1) was equal to $Z=3.5 \frac{\mathrm{m}}{\mathrm{kg}^{1 / 3}}$. The recorded pressure characteristic was compared with the idealized one (Fig. 2), which was determined with the use of the equation 2.

Tab. 1: Comparison of recorded pressure signal parameters with theoretical values

\begin{tabular}{lccc}
\hline Characteristic parameters of the signal & $\mathbf{P}_{\mathbf{s}}[\mathbf{M P a}]$ & $\mathbf{t}_{\mathbf{d}}[\mathbf{m s}]$ & $\mathbf{t}_{\mathbf{a}}[\mathbf{m s} \mathbf{~}$ \\
\hline Parameters of recorded pressure signal & 0.110 & 2.88 & 5.70 \\
\hline Parameters of idealised pressure signal (eq. 3-5) & 0.068 & 2.24 & 5.78 \\
\hline
\end{tabular}

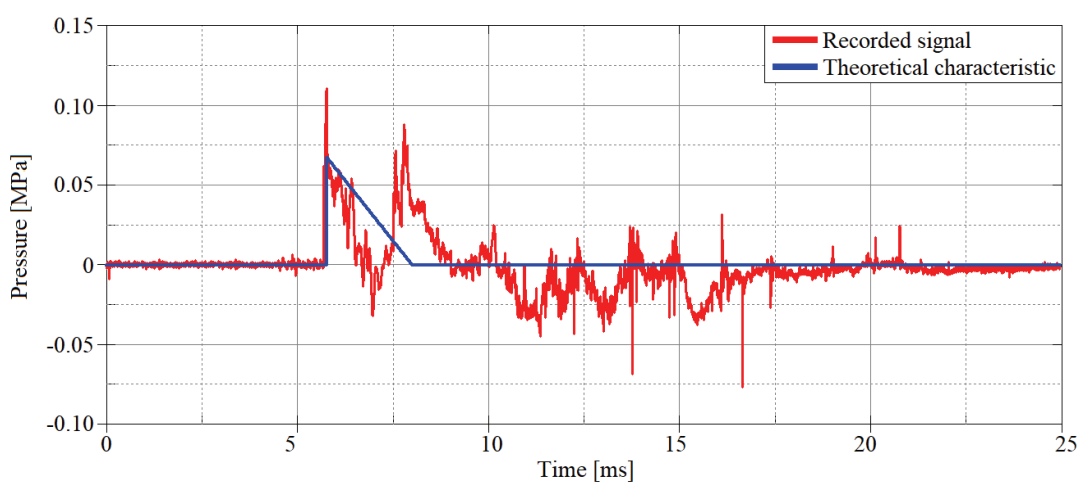

Fig. 2: Pressure characteristic recorded during explosion of $1.0 \mathrm{~kg}$ of TNT charge

According to the literature (Malhotra et al., 2017) overpressure of value $0.035 \mathrm{MPa}$ is a threshold point of eardrum rupture and at the value of $0.325 \mathrm{MPa}$ there is a $50 \%$ probability of it to happen. Therefore, the recorded value indicates a significant risk of eardrum damage. The obtained values of characteristic parameters were slightly higher than those predicted according to theoretical equations. However, it should be noted that equations 1-5 describe air blast without taking into account the wave reflection effect, which causes additional wave amplification and the appearance of a second pressure pulse as shown in the graph (Fig. 2).

The accelerations of the dummy head were shown on Fig. 3-6 and summarized in the Table 2.

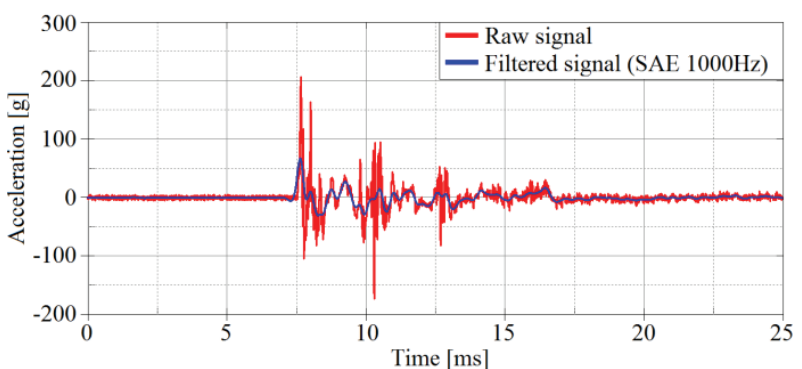

Fig. 3: Signal recorded for $0.075 \mathrm{~kg}$ of TNT

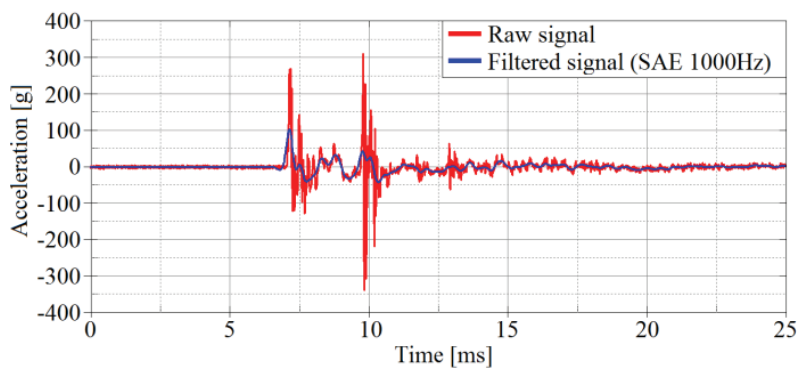

Fig. 4: Signal recorded for $0.2 \mathrm{~kg}$ of TNT 


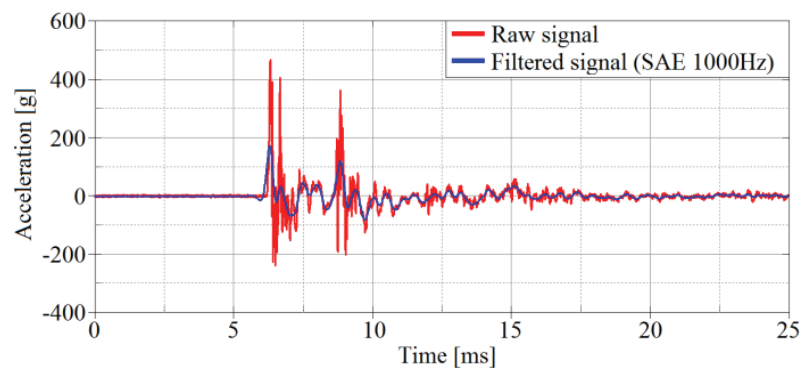

Fig. 5: Signal recorded for $0.4 \mathrm{~kg}$ of TNT

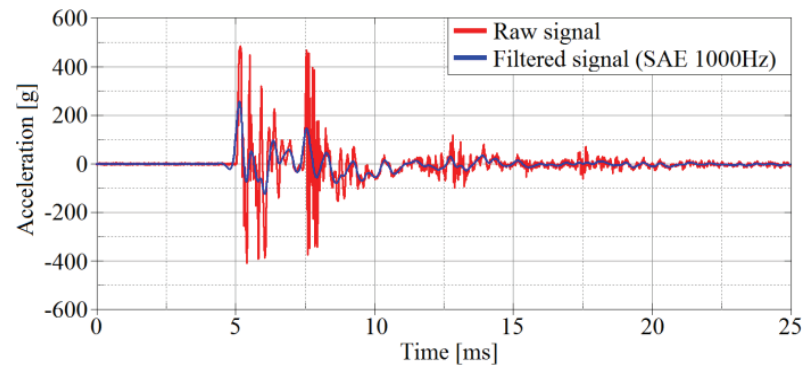

Fig. 6: Signal recorded for $1.0 \mathrm{~kg}$ of TNT

Tab. 2: Comparison of basic acceleration signal parameters for the dummy head

\begin{tabular}{ccccccc}
\hline \multicolumn{2}{c}{ TNT charge mass $[\mathbf{k g}]$} & & $\mathbf{0 , 0 7 5}$ & $\mathbf{0 , 2}$ & $\mathbf{0 , 4}$ & $\mathbf{1 , 0}$ \\
\hline \multirow{2}{*}{ Signal condition } & Signal parameter & Units & \multicolumn{3}{c}{ Values } \\
\hline \multirow{2}{*}{ Raw signal } & $\mathrm{a}_{\max }$ & {$[\mathrm{g}]$} & 207 & 311 & 468 & 487 \\
\cline { 2 - 7 } & $|\mathrm{a}|_{\text {avg_10ms }}$ (eq. 6) & {$[\mathrm{g}]$} & 18 & 24 & 37 & 62 \\
\hline \multirow{2}{*}{$\begin{array}{c}\text { Filtered signal } \\
\text { (SAE 1000Hz) }\end{array}$} & $\mathrm{a}_{\max }$ & {$[\mathrm{g}]$} & 67 & 103 & 172 & 256 \\
\cline { 2 - 7 } & $|\mathrm{a}|_{\text {avg_10ms }}$ (eq. 6) & {$[\mathrm{g}]$} & 10 & 14 & 25 & 36 \\
\cline { 2 - 7 } & HIC $_{15}$ (eq. 7) & {$[-]$} & 2 & 5 & 21 & 50 \\
\hline
\end{tabular}

The obtained values of $H I C_{15}$ were at an acceptable level according to NATO AEP-55 Vol. 2 (2011), where the values higher than 1000 are considered to be life threatening. In case of maximum average accelerations a slight differences between raw and filtered signals can be seen. Importance of this fact for the TNT charge masses of $0.4 \mathrm{~kg}$ and smaller were meaningless, but for $1.0 \mathrm{~kg}$ the raw acceleration signal exceeded the tolerance level of $45 \mathrm{~g}$ (Eiband et al., 1959), while for filtered signal it was acceptable.

\section{Conclusions}

Conducted studies showed that close proximity explosions of charges smaller than $1.0 \mathrm{~kg}$ of TNT were dangerous but not lethal to human. The recorded pressure characteristics highlighted the necessity of ear protection equipment usage. It was noticed that even for very high values of maximum accelerations, the $H I C_{15}$ coefficient did not exceed the allowable limit, thanks to extremely short impulse duration.

The issues with rapidly changing signal processing and interpretation were solved by providing both raw and filtered records. It can be seen that effective value of acceleration affecting the human body during explosion must lie between those two values. While the use of filters appropriate for car accidents helped with signal interpretation, the information about raw data contributed to the increase of overall reliability of obtained results.

\section{References}

Bienioszek, G. and Kciuk, S. (2017) Determination of boundary conditions for the optimization process of blast mitigation seat shock absorbers. Engineering Mechanics 2017, Brno Univ. of Technology, Brno, pp. 142-145.

Eiband, M. (1959) Human tolerance to rapidly applied accelerations. NASA Memorandum, Washington.

Krzystała, E., Kciuk, S. and Mężyk A. (2016) Minimisation of the explosion shock wave load onto the occupants inside the vehicle during trinitrotoluene charge blast. International Journal of Injury Control and Safety Promotion, 23:2, pp. 170-178.

Malhotra, A., Carson, D. and McFadden, S. (2017) Blast pressure leakage into buildings and effects on humans. Procedia Engineering, 210, pp. 386-392.

NATO AEP-55, Volume 2 (2011) Procedures For Evaluating The Protection Level of Armoured Vehicles.

Prat, N. J., Daban, J. L., Voiglio, E. J. and Rongieras F. (2017) Wound ballistics and blast injuries. Journal of Visceral Surgery, 154, pp. 9-12.

Szmidt, P., Kciuk, S., Mężyk, A. and Krzystała E. (2011) Autonomous measurement system for the acquisition of rapidly changing voltage signals. PL Patent, 219525.

Ullah, A., Ahmad, F., Jang, H. W., Kim., S. W. and Hong, J. W. (2017) Review of analytical and empirical estimations for incident blast pressure. KSCE Journal of Civil Engineering, 21, 6, pp. 2211-2225. 